\title{
Vessel charter rate estimation for offshore wind O\&M activities
}

\author{
Y. Dalgic, I. Lazakis \& O. Turan \\ Department of Naval Architecture \& Marine Engineering, University of Strathclyde, UK
}

\begin{abstract}
Estimating the cost of vessels is an important factor for the operation \& maintenance (O\&M) costs of offshore wind farms. Accurate cost estimation is required during operation of the wind farm. This paper presents the development of the O\&M charter rate modelling for offshore wind turbine jack-up vessels under different operational strategies. The main objectives of this modelling are to explore the differentiation of charter rates associated with the charter periods and with the capabilities of different vessels; as well as to allow offshore wind farm operators to plan their maintenance strategies through considering the share of vessels' costs in the overall maintenance costs. In this respect, various jack-up vessels in the offshore wind industry are investigated and the most effective charter periods are identified. The seasonal effects on the charter rates are also considered to provide critical insight into the selection of the optimum charter rate scenario.
\end{abstract}

\section{INTRODUCTION}

Over the past two decades, EU counties have been faced issues related to rapidly increasing population, economic depressions, and increased fossil-fuel prices. Following the realisation that renewable energy can be an alternative solution to the energy bottleneck, a tendency towards energy production from wind has been commenced. Furthermore, extremely challenging targets for 2020, which commit EU to reduce greenhouse gas emissions and increase the proportion of energy consumption from renewables by $20 \%$, have led to the pioneer countries investing more in wind energy.

The commercialism of wind power started with the very first onshore wind farm installations in USA by 1980 s. The availability of large areas in order to locate major projects, the lack of limitations associated with visual impact and noise, higher wind speeds, and the lower turbulence levels the in offshore environment encouraged operators to invest in offshore wind farms. Despite all these advantages, harvesting energy from offshore wind is still much more expensive than power generation from onshore wind farms. Taking into account the UK with the greatest operating capacity in its waters, offshore wind levelised cost of energy reached $£ 140 / \mathrm{MWh}$ in 2011 (The Crown Estate, 2012). More complicated foundations, longer electrical networks, installation and maintenance that are dependent on vessels, and harsher wind and wave conditions that limit the operability of vessels and subsequently the accessibil- ity of offshore wind farms for installation and maintenance activities can be considered the major factors that escalate the cost of offshore wind projects.

In the literature, detailed research has been done that consider the issues related to optimal design of turbines and foundations, failure characteristics of components, power production and transmission elements. Moreover, these issues have also been experienced by the investors and operators in onshore wind farm projects, which simplified the identification and problem solving for offshore wind turbines. On the other hand, Operation and Maintenance (O\&M) issues differ from onshore wind due to the influence of harsh environment and vessel dependency in order to transport personnel, equipment and perform maintenance activities. Therefore, there are great prospects to reduce the maintenance cost, which accounts $30 \%$ of the overall project budgets.

In this paper, an estimation process for daily charter rates associated with the vessels for major maintenance operations will be described. This study will be beneficial for the operators in order to plan offshore wind farm maintenance operations and evaluate different chartering options, which account for the major amount of the maintenance budgets.

The paper is structured as follows; in section 2, the common procedures, aspects and issues associated with maintenance of offshore wind farms will be presented. Through the observations in that section, the estimation process of different charter rates for offshore wind jack-up vessels will be explained in 
section 3. In addition, the influence of seasonality on the charter rates will be highlighted. In the conclusion section, results of the study and the recommendations will be presented.

\section{MAINTENANCE OF OFFSHORE WIND FARMS}

\subsection{Available vessels in the market}

The main tasks of the vessels in a maintenance operation are to provide accommodation for ship crew and technical personnel, loading, transporting and assembling failed turbine components in offshore environment. Due to the number of available vessels, their properties and the variety of benefits \& drawbacks of the vessels have to be taken into account in the vessel selection process, which allow operators eliminating either insufficient or oversize and unnecessary vessels which will increase the cost of operations (Table 1).

During the operational span of an offshore wind farm, a number of scheduled and unscheduled maintenance tasks have to be performed in order to keep the turbines operational and to sustain the power generation. In this respect, there are two main cat- egories of O\&M vessels in the offshore wind energy market: vessels for minor maintenance and vessels for major maintenance.

Vessels for minor maintenance are used for the minor repairs and technical problems, which do not require heavy equipment transport or heavy crane operations. In the case of minor repairs such as; electrical system, electronic control, sensor and hydraulic system repairs, vessels for minor maintenance are utilised in the operations.

Monohull boats, small catamaran vessels and Small Waterplane Area Twin Hull (SWATH) vessels are generally utilised in minor maintenance operations, which allow operators to keep the cost of minor maintenance operations at acceptable levels. Catamaran configurations are often the preferred choice but operations are restricted to relatively low wave heights. The most distinctive characteristics of these vessels are high speed, small deck spaces, small crane capacities and safe access to wind turbine structures that will allow operators to take quick actions in case of urgent repairs.

Due to the higher charter rates, jack-ups, legstabilised and heavy lifting vessels are not considered appropriate for minor maintenance operations. The capabilities of these vessels are also above and beyond the scope of minor repairs.

Table 1. Comparison of vessels currently employed in the offshore wind maintenance market

\begin{tabular}{|c|c|c|c|}
\hline Category & $\begin{array}{l}\text { Vessel } \\
\text { type }\end{array}$ & Benefits & Drawbacks \\
\hline \multirow[t]{3}{*}{$\begin{array}{l}\text { Vessels for } \\
\text { major mainte- } \\
\text { nance }\end{array}$} & Jack-ups & $\begin{array}{l}\text { - Specialisation for offshore wind farm projects } \\
\text { - Stable base for lifting operations } \\
\text { - Cost effective in medium and high wave areas } \\
\text { - Accommodation for both ship and maintenance } \\
\text { crew }\end{array}$ & $\begin{array}{l}\text { - Limited operational speed ( } \sim 10 \text { knots }) \\
\text { - Feeder vessels required } \\
\text { - Capability to operate up to } 50 \text { m water } \\
\text { depths } \\
\text { - Time consuming due to jacking opera- } \\
\text { tions }\end{array}$ \\
\hline & $\begin{array}{l}\text { Leg- } \\
\text { stabilised } \\
\text { vessels }\end{array}$ & $\begin{array}{l}\text { - Optimised choice related to water depth } \\
\text { - Ideal in shallow waters } \\
\text { - Quick transportation and installation capabilities }\end{array}$ & $\begin{array}{l}\text { - Limited number of vessels in the off- } \\
\text { shore market } \\
\text { - Limited sea state }(\sim 0.5 \mathrm{~m}) \\
\text { - Insufficient for future projects }\end{array}$ \\
\hline & $\begin{array}{l}\text { Heavy- } \\
\text { lifters }\end{array}$ & $\begin{array}{l}\text { - Very flexible for unusual cargo } \\
\text { - Heavy lift capacity } \\
\text { - Large quantity of cargo handling } \\
\text { - Relatively better stability characteristics }\end{array}$ & $\begin{array}{l}\text { - Low availability due to offshore oil and } \\
\text { gas industry } \\
\text { - Slower mobilisation } \\
\text { - Port entrance issues due to size } \\
\text { - Deep water precondition for operations } \\
\text { - Relatively higher daily charter rates (> } \\
£ 80,000)\end{array}$ \\
\hline \multirow[t]{3}{*}{$\begin{array}{l}\text { Vessels for } \\
\text { minor mainte- } \\
\text { nance }\end{array}$} & Monohull & $\begin{array}{l}\text { - Very high speed }(\sim 25 \text { knots }) \\
\text { - Safe access to turbines }\left(\mathrm{H}_{\mathrm{s}} \max <1 \mathrm{~m}\right)\end{array}$ & $\begin{array}{l}\text { - Limited passenger ( } 6 \text { to } 8 \text { ) and cargo ca- } \\
\text { pacity } \\
\text { - Insufficient for major repairs } \\
\text { - Uncomfortable for passengers, no other } \\
\text { facilities available }\end{array}$ \\
\hline & Catamaran & $\begin{array}{l}\text { - Medium speed }(\sim 20 \text { knots }) \\
\text { - Operational } \mathrm{H}_{\mathrm{s}} \max =1.8 \mathrm{~m} \\
\text { - Safe access to turbines }\left(\mathrm{H}_{\mathrm{s}} \max <1.2 \mathrm{~m}\right)\end{array}$ & $\begin{array}{l}\text { - Limited passenger ( } 12 \text { and more) and } \\
\text { cargo capacity } \\
\text { - Insufficient for major repairs }\end{array}$ \\
\hline & SWATH & $\begin{array}{l}\text { - Capacity of } 12 \text { to } 60 \text { passengers } \\
\text { - Medium speed }(\sim 15 \text { knots }) \\
\text { - Operational } \mathrm{H}_{\mathrm{s}} \max =2.5 \mathrm{~m} \\
\text { - Safe access to turbines }\left(\mathrm{H}_{\mathrm{s}} \max <1.5 \mathrm{~m}\right) \\
\text { - Comfortable for passengers }\end{array}$ & $\begin{array}{l}\text { - Limited cargo capacity } \\
\text { - Insufficient for major repairs }\end{array}$ \\
\hline
\end{tabular}


Major maintenance vessels are employed for either scheduled or unscheduled major repairs, which require lifting operations for heavy equipment. In the case of blade, generator or tower failures, small maintenance vessels cannot be adequate to perform the exchange of damaged components. Instead, one of the jack-up, leg-stabilised or heavy lift vessels have to be utilized considering the properties of damaged component (height, weight, etc.) and the capability of the vessel (lifting capacity, operational water depth, etc.).

Jack-ups are self-elevating units, which consist of a buoyant hull with a number of legs (generally 3 to 6 ), are capable of raising their hulls over the seasurface, station their legs on the sea floor and providing very stable environment for crane operations under rough sea conditions.

The operations of leg-stabilised vessels are very similar to the jack-up vessels. Instead of lifting the hull over the sea surface, leg-stabilised vessels, which are ideal for operations in shallow sites, use their legs to stabilise the hull. However, they have limited capability for crane operations due the fact that the vessels' hull remains submerged and are subject to wave-induced motion.

Heavy lifters are capable of lifting extensive loads, which can be experienced in offshore wind industry. These vessels possess the highest crane capabilities in offshore industry due to the fact that they are specially designed to install pre-assembled modules for offshore the oil and gas industry; however the daily charter rates are directly proportional to the crane capabilities.

At this point, it is important to highlight the fact that the number of leg stabilised vessels is considerably low in the market (EWEA, 2011). In addition, the charter rates of heavy lifting vessels are very high beyond compare (DNV, 2011). Therefore, jackup vessels/barges are the most utilised vessels for major maintenance operations in offshore wind energy market. However, the dependency on offshore oil and gas industry result in issues associated with lower availability in demanding months.

\subsection{Contractual arrangements and alternative chartering periods}

Voyage charter (spot market), time charter and bareboat charter are the commonly used three types of contractual arrangements in the maritime industry. The costs and individual responsibilities are distributed in a slightly different way (Figure 1). Under a voyage charter, the ship owner contracts to carry a specific cargo with a specific ship for a negotiated price per ton, which covers capital charges, daily running, and voyage costs. The time charter is an agreement between owner and charterer to hire the ship, complete with crew, for a fee per day,

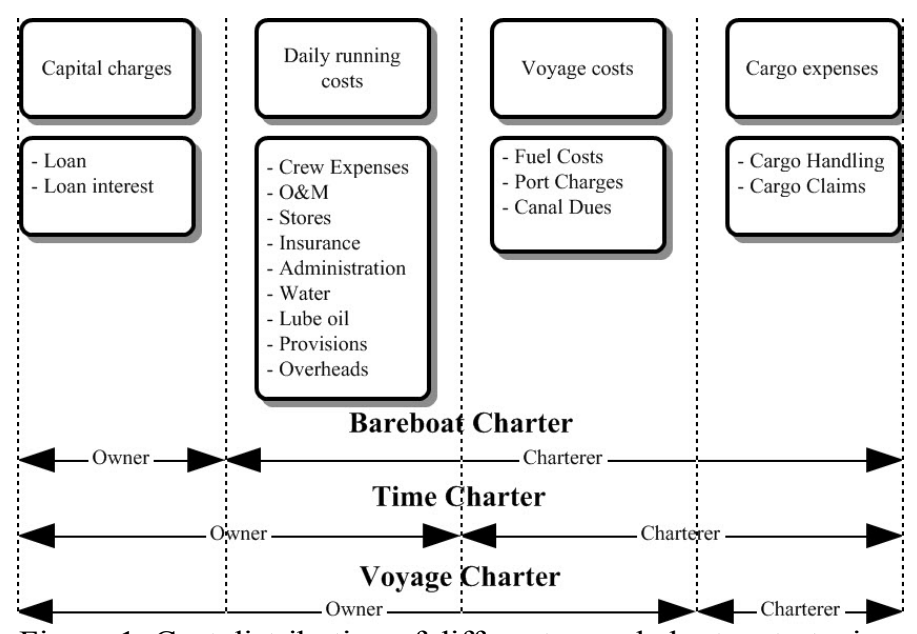

Figure 1. Cost distribution of different vessel charter strategies

month or year. In this case, the ship owner pays the capital costs and operating expenses, whilst the charterer pays the voyage costs. As a final point, the bareboat charterer hires out the ship without crew or any operational responsibilities, so in this case the charterer is responsible for daily running costs, voyage costs, and expenses related to cargo handling and claiming.

Offshore wind O\&M activities require extensive expertise and specialisation, due to the fact that very heavy components have to be lifted up to extreme heights in harsh environmental conditions. Therefore, operators may prefer to employ technicians and seafarers who have experience in offshore wind industry O\&M activities. In this respect, bareboat charter strategy is considered in the analyses in order to provide flexibility for operators to control every stage of the operations. Additionally, only the operators will have the authority to assess the costs and the risks related to specified O\&M operations.

Unplanned maintenance activities, catastrophic failures, and circumstances that require instant access to wind farms cause operators to hire vessels for a limited period ( $\sim$ month) in the spot market (Table 2). Short-term chartering is valuable for the wind farms that have sequential maintenance activities in a specified period, which can range from couple of months up to one year. Long-term chartering requires advanced scheduling for the maintenance operations. Due to the fact that the cost of vessels decreases if the charter period is longer, the risk associated is more significant. An alternative to reduce the risks is leasing the vessel to third parties, which can provide extra income for the operators.

However, the identification of the most appropriate vessel is not always sufficient to guarantee minimised vessel costs. The availability of such vessels and the length of the chartering period are vital for estimating the costs. GlobalData (2012) reported that in the installation period of The Alpha Ventus offshore wind farm, operators had to charter a vessel much larger and extremely expensive than originally planned due to the unavailability. 


\begin{tabular}{lll}
\hline Strategy & Advantages & Disadvantages \\
\hline Spot market & - Use vessel only after a failure of wind turbine & - Potential limited certainty in vessel availability \\
Min: $\sim 1$ month & occurs & - High uncertainty in mobilisation time and costs \\
Max: $\sim 3$ months & - Select optimal vessel for each turbine failure & - Day rates and mobilisation costs likely to be \\
& - Only use vessel when required & very high- Due to last minute arrangements, po- \\
& - Maximum utilisation of vessel & tential delays in mobilisation time and subse- \\
& & quently increased downtimes and loss of revenue \\
& - Reduces risk of weather effect (if performed & - Risk of low utilisation in winter \\
Short term charter & during summer) & - In case of maintenance/supply delays, risk of \\
Min: $\sim 3$ month & - Reduces number of vessel being chartered & uncompleted/imperfect repairs \\
Max: $\sim 1$ year & - Can be used across multiple sites & \\
& - Reduced mobilisation time and costs & \\
Long term charter & - Eliminated risk of vessel unavailability & - Paying for vessel even when not being used \\
Min: $\sim 1$ year & - Increased operational control/planning for the & - High initial investment \\
Max: $\sim 20$ years & offshore wind farm operators operator & - A management team required to operate the \\
& - Costs vary less over lifetime & vessel \\
& - Can use across multiple sites & - Repair and maintenance expenses potentially be \\
& - Better planning & added
\end{tabular}

\subsection{Failure rates and reliability assessment}

A commercial offshore wind turbine consists of a foundation, transition piece, tower, nacelle and blades. These major sections can contain 8,000 different components whose properties and failure rates have crucial importance on the vessel selection procedure and determination of related charter period. Weight, size and location of the components are important to specify the vessel capabilities and limitations. Operators have to consider the vessels that are capable of performing specified maintenance tasks. Failure rates are also essential with regard to determining the chartering period. Due to the fact that the utilisation level of maintenance vessels will be high in the case of high failure frequency rates, the selection of longer chartering periods can be cost effective. On the other hand, if the vessels cannot operate due to seldom failures and remain at port, this will lead to loss of revenue. In this case, chartering shorter periods or spot market alternatives can prevent the loss of revenue.

Faulstich et al. (2011) studied the failure rates of wind turbine components and the duration of downtimes related to these failures. Minor failures, which represent $75 \%$ of all failures, cause only $5 \%$ of overall downtime, on the other hand, major failures that represent $25 \%$ of all component failures account for $95 \%$ of all downtime duration. Spahic et al. (2009) showed that generators are the main cause of power systems unavailability. Haitao et al. (2009) analysed statistical failure rates and eventually recommended that gearbox downtimes have to be considered in order to improve the system availability. Tavner et al. (2007) analysed failure data of different offshore wind farms and indicated that the repair of mechanical subassembly failures is time consuming and costly, despite the fact that electrical control or system subassemblies have highest failure rates. The analyses results of Rademakers et al. (2003) showed that the blade, generator, and gearbox failures contribute to over $75 \%$ of the costs and the downtimes of the overall wind turbine.

In this respect, the influence of heavy component failures on the power generation interruptions and maintenance costs is more significant. Therefore, the maintenance planning and subsequently the cost associated with jack-up vessels has to be carefully determined.

\subsection{Cost of maintenance operations}

O\&M activities represent a significant share of the expenses during the lifetime of offshore wind farms. When compared to onshore wind, O\&M costs are increased for offshore, due to specialised vessels, shorter weather windows and rough environmental conditions, the occurrence of more failures, longer downtimes, decreasing availability and accessibility. Furthermore, the offshore environment involves personnel traveling to and from the offshore turbines, which increases equipment and labour costs as well as insurance costs. In generic, O\&M costs consist of labour costs, material costs, access vessels \& lifting vessels costs, and revenue losses.

In the warranty period of projects, which varies from 3 years to 5 years, the wind turbine manufacturers are responsible for the O\&M operations. However, $79 \%$ of wind turbines are set to move out of warranty, in less than five years (Evans, 2010). Therefore, operators have to plan the costs that they will bear in the future.

Fingersh et al. (2006) presented the costs associated with the offshore O\&M in order to keep the turbines operational, as $£ 140,000$ for maintenance \& overhauling and additional $£ 35,000$ for the replace- 
ment cost of irreparable components. Freeman (2011) reported that O\&M costs range from $£ 85,000$ to $£ 250,000$ per year for offshore wind farms, on the other hand, the operational costs remain limited to $€ 38,000$ per turbine in onshore wind farms. A recent study done by Kraemer (2012) supported the same aspect indicating that the O\&M cost is 2-6 times as high as onshore wind.

The distribution of O\&M costs is also important in order to identify the most critical sections, which can show the greatest impact on potential cost savings. The past studies proved that the development of new O\&M vessels is particularly important, since today the costs for vessels make up $73 \%$ of the total O\&M costs (Fingersh et al., 2006, Junginger et al., 2004, Krohn et al., 2009, Morgan et al., 2003). Van Bussel \& Zaaijer (2001) showed that irrespective of wind turbine design, the cost of lifting operations by using an external crane accounted for more than $50 \%$ of the overall O\&M costs. Complementary studies have been performed by Lazakis et al. (2012, 2013) by while Dinwoodie et al. (2013) evidenced that the vessel costs contribute the largest percentage of costs which is the key component of overall costs to control.

It is fully comprehended that the cost of vessels has the greatest potential to reduce the overall O\&M expenditures. However, the charter rates are determined by market. Therefore, from the charterer or operator point of view, accurate estimations towards better planning become more important in the offshore wind $\mathrm{O} \& \mathrm{M}$ activities.

\section{ESTIMATION OF VESSEL CHARTER RATES}

At the very first stage, it was important to identify available vessels and their technical specifications, which can change the charter rates significantly. In this respect, the jack-up vessel database of University of Strathclyde, Naval Architecture and Marine Engineering Department (NA-ME) and various other sources are investigated in order to develop a comprehensive list of technical specifications of the jack-up vessels. Crane capabilities, maximum operational water depths, maximum operational weather characteristics of the vessels become essential, when the maintenance of offshore wind farms is taken into consideration. Therefore, the vessels which have similar properties are subsumed under six different categories.

The list includes existing jack-up vessels, the ones under construction as well as the ones contracted for building, in order to include as many vessel options as possible, enable the evaluation of future contract scenarios, and ultimately increase the accuracy of the estimations. The specific technical characteristics of the offshore wind jack-up vessels for heavy O\&M is partially listed in Table 3 .

\subsection{Estimation of Charter Rates for Specified Periods}

The calculation of different charter rates for different charter periods was developed based on the O\&M scenarios identified in the previous section. The initially selected scenarios included the estimation of the vessels' charter rates for the following periods: spot market, charter of 1 year, and charter of 20 years. However, there are a number of attributes that influence the data gathering process undesirably; including

- Lack of offshore wind data,

- The confidentiality of available data among all the offshore wind market stakeholders,

- The low number of purpose-built vessels for the offshore wind market,

- The impact of negotiations between vessel owners and charterers/operators,

- The potential vessel unavailability due to high demand from offshore oil and gas industry

In this respect, other sources of information were utilised in order to overcome these difficulties such as;

- Naval Architecture and Marine Engineering (NAME) database of different offshore wind jack-up vessels,

- Authors' personal communication with experts in the offshore wind market,

- NAME own database of various ship type charter rates in the shipping industry,

- Investigation of similarities/differences between the offshore wind market and the shipping market in terms of the vessels employed and the relevant chartering options and accordingly rates,

- Experts judgement in the maritime industry for similar type of chartering periods,

- Examination of other relevant sources which present similarities with the offshore wind sector (e.g. offshore oil \& gas vessel databases, past studies/reports, etc.)

The CAPital EXpenditure (CAPEX), which is the capital invested by a company to acquire or upgrade fixed, physical, non-consumable assets, is proportional to the capabilities of the vessel. When the influence of the economic variations associated with the new building market is neglected, vessels with higher speed, better lifting capability (hook height, lifting tonnage, etc.), deeper operability and longer durability in harsher conditions have higher CAPEXs. With regard to charter rates, it was also anticipated that the vessels with better structural condition and with the ability to perform the O\&M activities more efficiently, would have higher hiring cost. Therefore, the relationship between the CAPEX of different vessels and associated charter rates for different periods was employed to establish the estimation of the rates for offshore wind vessels. 
Table 3. Extract of the technical specifications of jack-up vessels

\begin{tabular}{lllllllll}
\hline $\begin{array}{l}\text { Vessel } \\
\text { no }\end{array}$ & $\begin{array}{l}\text { Year } \\
\text { built }\end{array}$ & Loa & Beam & Draft & Speed & Crane capacity & Hook height & $\begin{array}{l}\text { Operational water } \\
\text { depth }\end{array}$ \\
\cline { 2 - 8 } & & $\mathrm{m}$ & $\mathrm{m}$ & $\mathrm{m}$ & knot & ton & $\mathrm{m}$ & $\mathrm{m}$ \\
\hline 1 & 2012 & 130.80 & 39.00 & 5.20 & 12.0 & 800 & 102.0 & 45.00 \\
2 & 2009 & 81.00 & 41.00 & 5.30 & 9.1 & 800 & 95.0 & 41.00 \\
3 & 2011 & 138.55 & 40.80 & 5.50 & 12.5 & 1000 & 104.0 & 40.00 \\
4 & 2003 & 130.00 & 38.00 & 4.30 & 11.0 & 300 & 87.0 & 35.00 \\
5 & 2012 & 151.00 & 50.00 & 5.12 & 9.0 & 1200 & 25.0 & 65.00 \\
6 & 2012 & 162.00 & 49.00 & 5.50 & 13.0 & 1200 & 33.0 & 55.00 \\
\hline
\end{tabular}

The initial step was the determination of the vessel charter rates for the 20 years period. Kaiser \& Snyder (2012) studied daily charter rates for offshore wind turbine vessels in 20-years charter period. The daily rates presented in their study, represent the average daily rates per vessel CAPEX for chartering a specific vessel over a period of 20 years. Following that, the relationship between the CAPEX and the daily charter rates was established considering a regression analysis model, taking into account an equivalent charter period of 20 years. This model was then used in order to estimate the 20-year charter rates for the CAPEX costs of the jack-up vessels present in the existing database. Table 4 shows the calculated daily charter rates for 20-year charter period for the vessels in Table 3. Charter rates vary from $£ 45,000$ to $£ 112,200$. As anticipated, the vessel with the lowest charter rate has the minimum qualifications to perform the O\&M activities, which may not be sufficient for some of the offshore wind farm sites. Conversely, the vessel with the highest charter rate is one of the newest vessels in the database and she possesses extensive capabilities in terms of crane capacity, hook height and speed in order to perform the O\&M activities.

Table 4. Charter rate estimation for 20 years charter period for offshore wind jack-up vessels

\begin{tabular}{llll}
\hline $\begin{array}{l}\text { Vessel } \\
\text { no }\end{array}$ & $\begin{array}{l}\text { Year } \\
\text { built }\end{array}$ & CAPEX & $\begin{array}{l}\text { Daily rates for a pe- } \\
\text { riod of 20-years }\end{array}$ \\
\cline { 3 - 4 } & & $£$ MM & $£$ \\
\hline 1 & 2012 & 102 & 67,800 \\
2 & 2009 & 86 & 58,200 \\
3 & 2011 & 176 & 112,200 \\
4 & 2003 & 64 & 45,000 \\
5 & 2012 & 141 & 91,200 \\
6 & 2012 & 160 & 102,600 \\
\hline
\end{tabular}

In order to estimate the charter rates for the rest of the initially selected scenarios (spot market, and charter period of 1 year), a number of additional steps were followed. At first, the NAME database including the shipping market charter rates for different types of vessels was taken into account. Although the offshore wind vessel market does not explicitly operate in the same way as the shipping vessel market, large bulk carriers were used due to their CAPEX similarity as well as their charter rates presenting a representative trend over specified chartering scenarios. In this case, the charter rates for various bulk carrier types of ships for the last 8 years (from 2004 to 2012) were examined. In this period, shipping market experienced peak and bottom figures in terms of both CAPEX and charter rates. Therefore, the estimations through the analyses of these rates would be beneficial to capture regular charter rates instead of charter rates under extreme economic circumstances.

As the original offshore wind jack-up vessel database included the CAPEX of these vessels, it would be preferable if a formulation was retrieved describing the relationship between the vessels' CAPEX and their equivalent charter rates. Although the offshore wind vessel market does not explicitly operate in the same way as the shipping vessel market, these vessels were used due to their CAPEX similarity as well as due to their charter rates presenting a similar trend over similar trading/chartering scenarios for specific chartering periods.

Therefore, the relationship between the ships' CAPEX and 1-year charter rate was established. Various options were initially considered in order to achieve the optimum approximation in terms of the combination of CAPEX of all bulk carriers. The same steps were also followed for the combination of the 1-year charter rates for the same bulk carriers. The entire process was not an easy task to achieve. That is because the bigger ship types (Capesize bulk carriers) have smaller ratio of charter rates to CAPEX, thus the obtained charter rates were quite low. On the other hand, smaller ship types have larger ratio of charter rates to CAPEX, which result in tremendously high estimations. Hereafter, different combinations of data including different bulk carrier types and their equivalent charter rates over the years were also attempted. Eventually, reasonable values were achieved including the combination of all vessels (all bulk carriers) and their equivalent charter rates for a period of the last 8 years. Table 5able 5 represents the estimated daily charter rates for the vessels under 1-year charter. Due to the reduction in charter period, the rates showed an increment about $70 \%$, which is considerably high; especially the efforts to decrease the costs are considered. According to experts in the offshore wind market, this level of increase has been experienced in the past projects. 
Table 5. Charter rate estimation for 1-year charter period for offshore wind jack-up vessels

\begin{tabular}{llll}
\hline $\begin{array}{l}\text { Vessel } \\
\text { no }\end{array}$ & $\begin{array}{c}\text { Year } \\
\text { built }\end{array}$ & CAPEX & $\begin{array}{l}\text { Daily rates for a pe- } \\
\text { riod of 1 year }\end{array}$ \\
\cline { 3 - 4 } & & $£$ MM & $£$ \\
\hline 1 & 2012 & $£ 102$ & 117,200 \\
2 & 2009 & $£ 86$ & 96,400 \\
3 & 2011 & $£ 176$ & 213,400 \\
4 & 2003 & $£ 64$ & 67,800 \\
5 & 2012 & $£ 141$ & 167,900 \\
6 & 2012 & $£ 160$ & 192,600 \\
\hline
\end{tabular}

The next step involved the estimation of the charter rates for the offshore wind jack-up vessels for the spot market. Due to the same reasons mentioned before for the estimation of the charter rates for the 1year charter period (i.e. not sufficient data available, confidentiality issues, etc.), NAME's database for different ship types operating in the maritime sector and providing values on the spot market rates were also used. Once again, a variety of combinations of different bulk carrier ships and their equivalent charter rates was employed.

Eventually, it was decided to use data of Capesize ships and their charter rates. This was also performed since the spot market charter rates of Capesize bulk carriers were similar to the ones of the jack-up vessels as well as due to their similar high capital costs. In this case, the spot market rates for a period of 4 years (from 2007 to 2010) was selected to be examined, including rates while the shipping market was in different operational mode (low and peak times). A similar way in the calculation of the relationship between the 1-year charter rate and the spot rate was followed.

In this respect, the summarised results for the spot market rates are demonstrated in Table 6 .

Table 6. Charter rate estimation for spot market for offshore wind jack-up vessels

\begin{tabular}{llll}
\hline $\begin{array}{l}\text { Vessel } \\
\text { no }\end{array}$ & $\begin{array}{l}\text { Year } \\
\text { built }\end{array}$ & CAPEX & $\begin{array}{l}\text { Daily rates for a } \\
\text { spot market }\end{array}$ \\
\cline { 3 - 4 } & & $£$ MM & $£$ \\
\hline 1 & 2012 & 102 & 160,400 \\
2 & 2009 & 86 & 133,000 \\
3 & 2011 & 176 & 287,400 \\
4 & 2003 & 64 & 95,300 \\
5 & 2012 & 141 & 227,300 \\
6 & 2012 & 160 & 259,900 \\
\hline
\end{tabular}

Moreover, Figure 2 shows the rates of the jack-up vessels for all chartering period alternatives. The variation of daily charter rates associated with the chartering periods becomes more conspicuous when the spot market charting alternative is considered, due to the fact that the vessels in high CAPEX region will present lower availability than lower CAPEX region for shorter chartering periods. For instance, the variation of CAPEX from $£ 100$ million to $£ 150$ million results in an escalation of $£ 30,000$ for 20-year charter rates; on the other hand, same

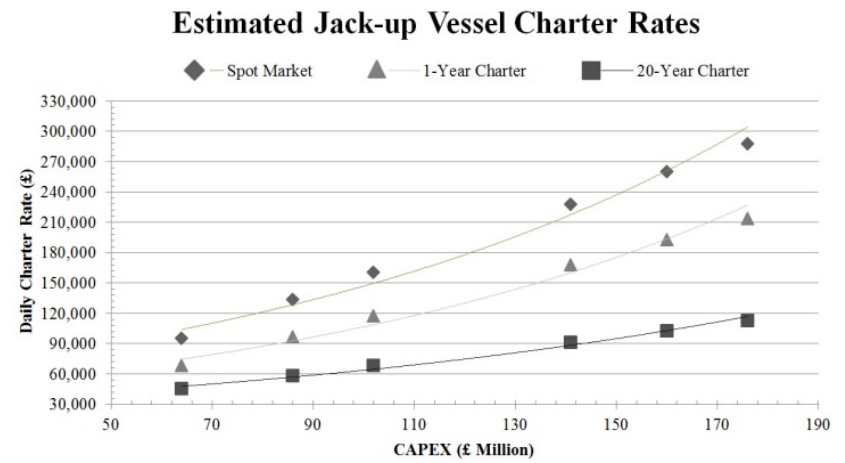

Figure 2. Estimated charter rates for wind turbine jack-up vessels

variation can influence the charter rates of spot market almost $£ 85,000$. The analyses results show that correct vessels selection considerably important due the fact that oversize and unnecessary vessels increase the charter rates extremely.

\subsection{Seasonality}

In addition to what has been discussed so far, it is well known that the charter rates of jack-up vessels vary considerably depending on the season in which the operators/developers intend to hire the vessels. As harsh weather conditions restrict the maintenance operations in the offshore environment, thus decreasing the demand, it is expected that the charter rate for jack-up vessels will be at the lowest level during winter months. Furthermore, power ratings are higher in winter than in summer, due to the lower ambient temperature, and there is a low probability that the weather can disturb maintenance operations. In addition, monthly capacity factors show lower trend in summer seasons, which also decrease the power generation. Due to these reasons, operators plan their maintenance activities in summer seasons, which increase demand for offshore wind vessels.

In this respect, the scarcity of data and the immaturity of the offshore renewable market do not provide an accurate sample size of charter rate data. In order to overcome this obstacle, charter rates from the bulk carrier shipping market were employed in order to address the seasonality effect. In this case, a similar seasonality trend appears in terms of the number of working days and availability of vessels trading both for bulk carrier ships and offshore wind maintenance vessels. Moreover, bulk carrier ships show similar properties in terms of CAPEX and vessel dimensions compared to the offshore wind maintenance vessels, which also strengthens the seasonality relation the vessels discussed. The mean values for all the charter rates were calculated, while after that, all the charter rates were differentiated according to the winter, spring, summer and autumn seasonality. The comparison of the mean values for winter and summer can be seen in Figure 3. 

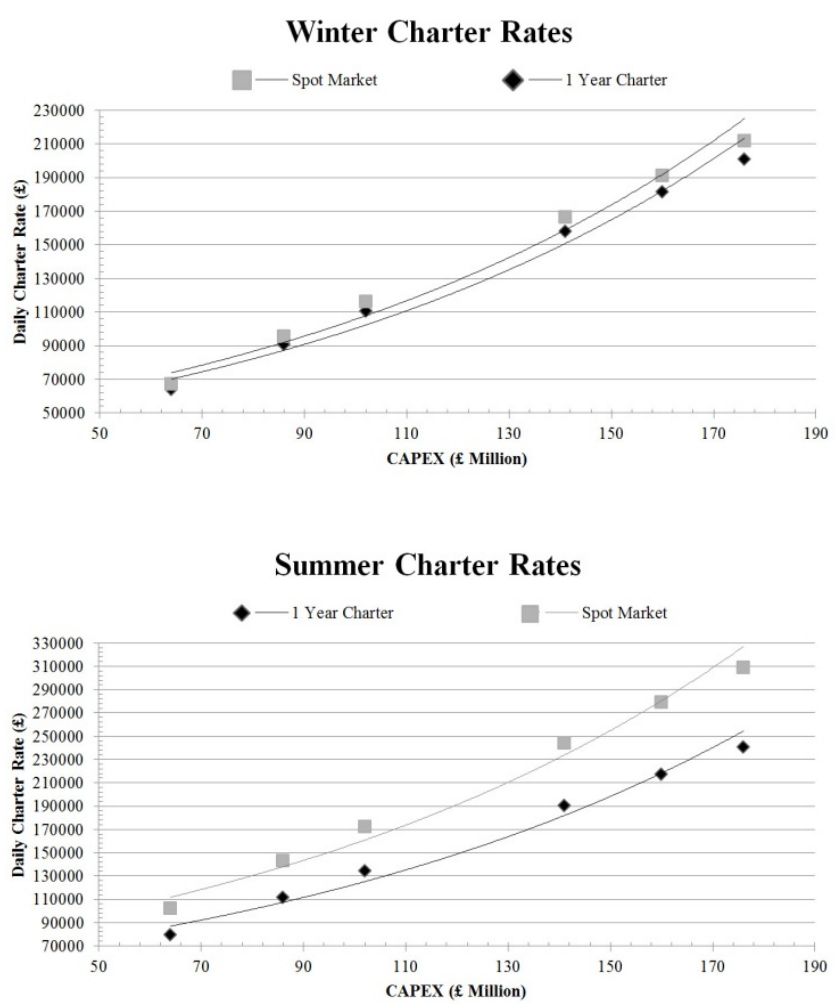

Figure 3. Seasonality influence for wind turbine jack-up vessels

The comparison of summer and winter rates show that charter rates in summer are significantly higher than winter. Furthermore, there is stronger variation in summer due to CAPEX increment. The reason behind this variation is the number of vessels in higher CAPEX region is very limited; therefore, in peak season their daily charter rates increase more than the vessels in lower CAPEX region.

\section{CONCLUSIONS}

Up until now, offshore wind farms have mostly relied on products and technologies used in onshore wind farms as well as the oil and gas industry. This situation results in inefficiency, which prevents the unlocking of the full potential of offshore wind. O\&M at sea poses totally different challenges to operators than servicing turbines onshore, whilst relying on heavy lift vessels from the oil and gas industry drives costs up significantly.

In accordance with the results, there is great advantage to hire the vessels for longer periods of time. However, there are also some investment risks, which operators have to bear in mind. These risks can be mitigated through sophisticated maintenance approaches and more accurate planning. In this respect, a separate management team, which is responsible from only vessel management, has to be utilized by the companies in order to keep the vessel operating.
Due to the fact that spring and summer months are more appropirate for maintenance activities in terms of both milder weather conditions and lower production levels, operators intend to perform maintenance activities in this period. Therefore, the number of available vessels in summer months decreases, subsequently the charter rates of the jackup vessels increases. In term of seasonalty of the charter rates, it is important to highlight that the results can be improved if more jack-up related data is made available in order to enable further validation of the mentioned results.

As the number of turbines in offshore wind projects increases, and because the wind farms are further from shore, there is a need to develop new O\&M vessels. Today's jack-up vessels have approximately $65 \mathrm{~m}$ operational water depth limit. In the future, jack-up vessels will not be sufficient for the maintenance operations due to the extreme depths. If designers/developers do not/design build floating offshore wind turbine maintenance vessels, the dependency to the offshore oil and gas industry will sustain and thus charter rates will continue to be determined by external players. In order to eliminate the dependency on oil and gas industry, a shift from port-based to offshore-based strategies can be a solution as well. Innovative approaches, such as mothership concept, can be the way to decrease the cost for offshore wind parks O\&M activities.

\section{ACKNOWLEDGEMENTS}

The authors wish to thank the offshore renewable experts to present study providing their comments and valuable feedback.

\section{REFERENCES}

DINWOODIE, I., MCMILLAN, D., REVIE, M., LAZAKIS, I. \& DALGIC, Y. (2013) Development of a Combined Operational and Strategic Decision Support Model for Offshore Wind. Energy Procedia (accepted for June 2013 publication), -.

DNV (2011) Design of Offshore Wind Turbine Structures. Norway, DNV.

EVANS, T. (2010) Proven Operations and Maintenance Strategy, Technology and Equipment Demanded by Wind Operators. Wind Energy Update.

EWEA (2011) Wind in our Sails - The coming of Europe's offshore wind energy industry. IN AZAU, S. \& CASEY, Z. (Eds.). Brussels.

FAULSTICH, S., HAHN, B. \& TAVNER, P. J. (2011) Wind turbine downtime and its importance for offshore deployment. Wind Energy, 14, 327-337.

FINGERSH, L., HAND, M. \& LAXSON, A. (2006) Wind Turbine Design Cost and Scaling Model. National Renewable Energy Laboratory. 
FREEMAN, P. (2011) Operations and maintenance costs "continue to skyrocket". Wind Energy Update.

GLOBALDATA (2012) Healthy competition: demand grows for specialised offshore vessels. World Expro.

HAITAO, G., XIANHUI, Y., JIANPING, X. \& WATSON, S. (2009) Wind turbine availability analysis based on statistical data. International Conference on Sustainable Power Generation and Supply, 6-7 April 2009. Nanjing, China.

JUNGINGER, M., FAAIJ, A. \& TURKENBURG, W. C. (2004) Cost reduction prospects for the offshore wind energy sector. Wind Engineering, 28, 97-118.

KAISER, M. J. \& SNYDER, B. F. (2012) Modeling offshore wind installation vessel day-rates in the United States. Maritime Economics \& Logistics, 14, 220-248.

KRAEMER, S. (2012) O\&M Offshore wind: offshore gas \& oil predictive maintenance technology could provide wind farms with lower costs; competitive advantage. Wind Energy Update.

KROHN, S., MORTHORST, P.-E. \& AWERBUCH, S. (2009) The Economics of Wind Energy. Brussels, EWEA.

LAZAKIS, I., TURAN, O. \& ROSENDAHL, T. (2012) Risk assessment for the installation and maintenance activities of a low-speed tidal energy converter. International Conference on Marine and Offshore Renewable Energy, 26-27 September 2012. London, UK.
LAZAKIS, I., TURAN, O. \& ROSENDAHL, T. (2013) Modelling of vessel and equipment cost for the maintenance activities of an offshore tidal energy array. Proceedings of the PRADS2013, 20-25 October 2013. Changwon City, Korea.

MORGAN, C., SCOTT, N. C. \& SNODIN, H. M. (2003) Economies of Scale, Engineering Resource and Load Factors. London.

RADEMAKERS, L. W. M. M., BRAAM, H., ZAAIJER, M. B. \& VAN BUSSEL, G. J. W. (2003) Assessment and optimisation of operation and maintenance of offshore wind turbines. Proceedings of the European Wind Energy Conference, 16-19 June 2003. Madrid, Spain.

SPAHIC, E., UNDERBRINK, A., BUCHERT, V., HANSON, J., JEROMIN, I. \& BALZER, G. (2009) Reliability model of large offshore wind farms. IEEE Bucharest PowerTech, 28 June-2 July 2009. Bucharest, Romania.

TAVNER, P. J., XIANG, J. \& SPINATO, F. (2007) Reliability analysis for wind turbines. Wind Energy, 10, 1-18.

THE CROWN ESTATE (2012) Offshore Wind Cost Reduction Pathways Study. London.

VAN BUSSEL, G. J. W. \& ZAAIJER, M. B. (2001) Reliability, availability and maintenance aspects of large-scale offshore wind farms, a concepts study. Proceedings of MAREC Marine Renewable Energies Conference, March 2001. Newcastle, UK. 